DOE/ER/13666--6

DE93 012556

\title{
CHEMICALLY MODIFIED ELECTRODES AND RELATED SOLUTION STUDIES
}

\author{
TECHNICAL \\ Final Progeso Report \\ for Period January 15, 1991 - January 14, 1992
}

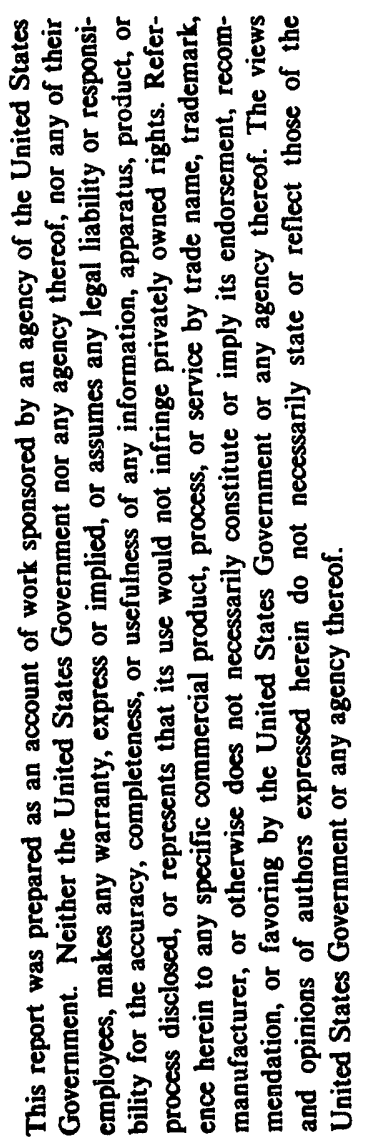

\author{
Colorado State University \\ Fort Collins, CO 80523
}

April 1993

Prepared for

THE U. S. DEPARTMENT OF ENERGY

AGREEMENT NO. DE-FG02-87ER13666 


\section{$\mathrm{Ru}_{4} / \mathrm{Fe}$ Complexes of Tetra(4'-methyl-2,2'-bipyridine)porphyrin--Catalytic Epoxidation of Olefins}

A number of high valent iron ferryl porphyrin-containing enzymes, such as cytochrome P450, can effect epoxidations of olefins. Simple iron porphyrins do not for two reasons: formation of the ferric $\mu$-oxo dimer species and self oxidation. We have synthesized and studied heteropolynuclear porphyrin complexes analogous to TPP where the four pendant phenyl groups are replaced with four trisbipyridine ruthenium (I) groups or a polymerizable analog containing vinyl substituents on each of the remote bipyridines(II).

For steric and electrostatic reasons $\mu$-oxo species do not form in solution from I. Also, the oxidation potentials of the four peripheral $\mathrm{Ru}(\mathrm{bpy})_{3}$ groups (to $\mathrm{Ru}^{3+}$ ) coincides closely with the first oxidation of the iron porphyrin (beyond the formal $3+$ state). Our rationale was that oxidation of this complex from appropriate aqueous solutions could produce a species similar to the active form of the various peroxidase-type enzymes and that such a species might carry out epoxidations of carbon-carbon double bonds.

Homogeneous solution studies in acidic aqueous/acetone containing any of a wide variety of olefins show a modest catalytic current, the onset of which coincides with the oxidation of the complex. This activity can be most clearly demonstrated with ethylene or propylene which can be added and removed (by $\mathrm{N}_{2}$ purge) several times to show unambiguously that the catalytic current is due to the presence of the olefin.

In addition to providing up to four oxidizing equivalents directly to the porphyrin core, the $\mathrm{Ru}(\mathrm{bpy})_{3}$ groups have provided a means whereby the complex can be made polymerizable. Complex II, above, has been prepared and reductively polymerized onto electrode surfaces. A number of advantages are inherent in producing polymers of this porphyrin. First, by immobilizing it, the oxidized form cannot access other porphyrins and carry out undesirable side reactions that might degrade the catalyst. Second the poly-Ru(bpy) 3 back bone can serve as a "molecular wire" putting the porphyrin in indirect electrical contact with the electrode. Finally, while it was not predicted a priori, the activity of the catalyst in the electrode bound form is considerably enhanced over that in homogeneous solution. This last observation is not unique to this system; several examples now exist where the very act of incorporating redox catalysts into electrode bound films either enhances activity greatly or introduces activity that is absent from the isolated monomer (this point will be considered again in the proposal).

Preliminary experiments had suggested that the product of electrochemical oxidation of olefins at electrodes modified with films of II were predominantly epoxidation products (rather than radical, allylic oxidations). Much of our recent effort has been directed at trying to find conditions where we could detect these epoxidation products directly. Unfortunately, what we have discovered is that, unless the electrochemical solution is strongly acidic, the polymer is unstable to oxidation (most probably due to the generation of hydroxyl radicals which destroy the porphyrin). Under strongly acidic aqueous conditions none of the initially generated epoxides are stable to hydrolysis. We have, however, determined indirectly that the oxidation product is almost certainly the epoxide. Both gas chromatographic and NMR analysis of electrolysis solutions show that the near exclusive ultimate product of cyclohexene oxiation is the trans-diol. Very little cyclohexenol or cyclohexenone is produced. Since the trans-diol is the expected product of the hydrolytic ring opening of the corresponding epoxide we take this as strong indirect proof of epoxidation.

\section{Water Oxidation Catalysis by Doubly Linked $\mu$-oxo Ruthenium Complexes}

Several variations on the dinuclear ruthenium complex $(\mathrm{L})_{2}\left(\mathrm{H}_{2} \mathrm{O}\right) \mathrm{Ru}-\mathrm{O}-\mathrm{Ru}\left(\mathrm{H}_{2} \mathrm{O}\right)(\mathrm{L})_{2}$, where $L$ is $2,2^{\prime}$-bipyridine or a substituted bipyridine, have been prepared and examined with 
respect to their activity towards the oxidation of water to $\mathrm{O}_{2} \cdot{ }^{1-3}$ This reaction is of considerable interest and energetic importance, for example, in potential photochemical water splitting reactions.

Because of our interest in developing electrode bound films containing a catalyst of this sort, we developed a synthetic strategy for preparing analogs of this complex in which two of the bipyridine ligands, one on each ruthenium, are linked by alkyl chains of various lengths. ${ }^{3}$ Briefly, we were interested in stabilizing the Ru-O-Ru linkage to cleavage, and in the event of cleavage, to hold the two rutheniums together so that the $\mu$-oxo bridge could be reformed.

Thus far our studies of these systems have been confined to homogeneous solution. Observations from these studies indicate that the alkyl linked systems function better as $\mathrm{O}_{2}$ evolution catalysts than the parent, non-alkyl linked complex. ${ }^{3}$ These studies also strongly suggest that, contrary to mechanisms proposed previously in the literature ${ }^{1}$, the $\mathrm{O}_{2}$ does not result from a concerted unimolecular four electron process involving both coordinated $\mathrm{H}_{2} \mathrm{O}$ molecules. In general, the linked complexes evolve $\mathrm{O}_{2}$ significantly more rapidly than does the non-linked complex. They are more stable, at least in that they remain catalytically active for longer periods. Additionally, they evolve $\mathrm{O}_{2}$ with apparently higher current efficiency' than does the simple, non-linked system.

Molecular modeling studies using Biograf ${ }^{4}$ software indicates that the energy minimized structures are very similar to the published crystal structure of the non-linked system except for the energy required to rotate around the $\mathrm{Ru}-\mathrm{O}-\mathrm{Ru}$ bond. All of the linked complexes are locked into fairly rigid conformations where the angle formed between the two coordinated waters depends both on the chain linking the bipyridines and on which isomer is modeled. The non-linked system, in contrast, is relatively free to rotate about the $\mu$-oxo bond. Finally, from our modeling studies we have determined that a $\mu$-oxo- $\mu$-peroxo- intermediate in the evolution of $\mathrm{O}_{2}$ is energetically completely unreasonable.

Polymer Films Formed by Oxidation of Transition Metal Electrodes into Solutions of Bisbipyridinealkane Ligands.

The series of ligands used to prepare the linked dinuclear complex described in the previous section, has now been extended to include all alkyl chain lengths from $n=2$ to $7 .^{5}$ One can demonstrate using molecular models that when there are 7 or fewer carbons in the linking chain it is not sterically possible to bind both bipyridines from the same ligand molecule to a single metal. With metals that have a high formation constant for forming a trisbipyridine complex, for example $\mathrm{Fe}^{2+}$, one might expect to form an insoluble, highly crosslinked polymer when the metal ion is combined with a bisbipyridinealkane ligand in the proper stoichiometry. In fact, this result is observed. Consequently, we were led to attempt the preparation of polymer films of trisbipyridine metal complexes by generating the metal ion electrochemically in the presence of bisbipyridinealkane ligands.

The reasons for our interest in this study are several fold. First, we wished to determine if electroactive polymer films could be formed in this way. Second, a number of analogous $\mathrm{M}(\mathrm{bpy})_{3}$ polymers have been formed by reductive polymerization of vinylbipyridine containing monomers, and we were interested in comparing oxidatively formed polymers with these. Finally, only a relatively few vinyl bipyridine and vinyl pyridine metal complexes are amenable to reductive polymerization (e.g. $\mathrm{Co}^{2+}$ complexes are not); therefore, this new oxidative route holds promise as a means for forming electroactive metal complex-containing films of catalytic interest that are simply not accessible by other routes.

As with iron, oxidation of cobalt electrodes into solutions of bisbipyridinealkane ligands produces electroactive films containing $\mathrm{Co}(\mathrm{bpy})_{3}$. Abruña and coworkers have previously 
- observed significant catalytic activity toward $\mathrm{CO}_{2}$ reduction by electroactive films containing the closely analogous complex, Co(terpy) 2 , (where terpy is the tridentate terpyridine ligand). The ability to form $\mathrm{Co}(\mathrm{bpy})_{3}$ polymer films oxidatively has allowed us to examine their electrochemistry and their interactions with $\mathrm{CO}_{2}$.

In solution, when $\mathrm{Co}(\mathrm{bpy})_{3}{ }^{2+}$ is reduced by two electrons beyond the $2+$ state, one of the bipyridine ligands is lost, giving rise to irreversible electrochemistry. In contrast, in these polymer films the second reduction of $\mathrm{Co}(\mathrm{bpy})_{3}$ is electrochemically reversible, indicating that either no ligand is lost or that the ligand is lost reversibly on the electrochemical time scale.

The introduction of $\mathrm{CO}_{2}$ to the solution has an interesting effect on the electrochemical properties of the polymer film which we yet do not fully understand. In acetonitrile solution in the absence of $\mathrm{CO}_{2}$ the film is yellow/brown in the $2+$ oxidation state, royal blue in the $1+$ state and blue/black in the formal zero state. When the solution is saturated with $\mathrm{CO}_{2}$ and the potential is cycled only through the first reduction (1+ oxidation state) no change in the electrochemistry of the film is noted. However, when the potential is scanned into the second wave the current is decreased dramatically and the film remains blue indicative of the 1+oxidation state. Upon the second and subsequent scans the current for both the first and second waves are greatly diminished and the film remains blue at positive potentials. If the solution is subsequently purged with $\mathrm{N}_{2}$ to remove the $\mathrm{CO}_{2}$ the film's electroactivity returns. Clearly, some reaction between the zero oxidation state film and $\mathrm{CO}_{2}$ is occurring which reversibly passivates the film. We speculate that possibly $\mathrm{C}_{2} \mathrm{O}_{4}{ }^{2-}$ ion is being formed which electrostatically crosslinks the film and restricts ion transport. We are attempting to determine if this, in fact, it the correct explanation.

\section{Polymer Films Containing $[\mathrm{CpMo}(\mu-\mathrm{S})]_{2} \mathrm{~S}_{2} \mathrm{CHR}$ Dinuclear Clusters}

We have previously reported on the preparation and electrochemical properties of polymer films containing dinuclear [CpMo( $\mu-\mathrm{S})]_{2} \mathrm{~S}_{2} \mathrm{CH}_{2}$ complexes. ${ }^{6}$ In these polymer films we were able to effect similar reactions electrochemically to those observed in solution. However, the mode used to attach the complex to the polymer left only a single sulfur site un-alkylated. In solution, the dinuclear complex having two un-alkylated cis-silfur sites is much more reactive in a number of interesting reactions (including multiple bond hydrogenations) than is the analogous complex having only one free sulfur. ${ }^{7}$ For this reason we undertook to prepare polymers having two cis-sulfur sites free. Our strategy was to prepare preformed polymers with reactive gem-dihalide groups that we then planned to react with the totally un-alkylated molybdenum species. In this way the complex would be bridged to the polymer by two cis-sulfurs leaving the remaining two free. Our efforts in this regard have been disappointing. We prepared a number of soluble polymer substrates containing the required gem-dihalide functions, but these proved too unreactive for successful attachment chemistry with the molybdenum complex. Our most promising idea in this work was to prepare a soluble dichloromethyl-polystyrene. This polymer should have the necessary reactivity for attachment to the complex while still being soluble. The specific strategy was to take commercially available, soluble monochloromethylpolystyrene, oxidize it selectively to the polyvinyl-benzaldehyde and then convert the formyl group to the desired dichloromethyl function by standard synthetic means. Basically, this strategy worked well except for one fatal problem; namely, during the course of the oxidation a minor side reaction occurs which crosslinks the the polymer and rendered it insoluble. The conversion to the aldehyde polymer was virtually complete (based on IR spectroscopy) as was the subsequent conversion of the formyl group to a dichloromethyl, but the polymer remained insoluble. Consequently, the material could not be cast into films on electrodes.

\section{Conducting Polymer Films for Catalyst Incorporation}

A number of studies have been conducted on the synthesis and fundamental properties of 
conducting polymers. Understanding these materials and preparing new conducting polymers are important aspects of developing electroactive films with catalytic redox properties. We have investigated the mechanism of polymerization of several vinyl containing metal complexes that are of direct relevance to work proposed here. From these studies it has been determined that the mechanism of polymerization is radical chain growth rather than hydrodimerization as previously proposed. 8,9

Intimately associated with any redox process occurring in an electroactive polymer film are electron and ion transport. We have conducted a number of studies at better understanding these phenomena in a variety of types of conducting polymers including poly-metal complexes, ${ }^{8-11}$ organic conducting polymers, 12,13 and conducting polymer composites. ${ }^{14}$ Each of these studies has contributed considerably to our understanding of how to design electroactive polymers into which redox catalysts may be incorporated. 
REFERENCES

1. (a) Gilbert, J. A.; Eggleston: D. S.; Murphy, W. R. ; Geselowitz, D. A.: Gersten, S. W.: Hodgson, D. J.; Meyer, T. J. J. Am. Chem. Soc. $1985,107,3855$. (b) Takeuchi, K. J. ; Samuels, G. J.; Gersten, S. W.; Gilbert, J. A.; Meyer, T. J. Inorg. Chem. 1983, 22, 1407. (c) Mayer, B. A.; Meyer, T. J. Inorg. Chem. 1981, 20, 436 .

2. Rotzinger, F. P.; Munavalli, S.; Comte, P.; Hurst, J. K. ; Gratzel, M.; Pern, F-J.; Frank, A. J. J. Am. Chem. Soc. 1987, 109,6619 .

3. Petach, H. H.; Elliott, C. M. Inorganic Chemistry, submitted June 1991.

4. (a) Biograf obtained from Bio-Design subsidiary of Molecular Simulations Inc., 199 S. Los Robles Ave., Pasadena, CA 91101. (b) Rappe', A. K.; Goddord, W. A. J. Phys. Chem., 1991, 95, 3358. (c) Mayo, S. L.; Olafson, B. D.; Goddord, W. A. J. Phys. Chem., 1990, 94, 8897 .

5. Schmehl, R. H.; Ryu, C. K.; Elliott, C. M.; Headford, C. E. L.; Ferrere, S. A.C.S., Adv. in Chem. Ser., 1990, 211.

6. Casewit, C. J.; Dunkle, J. R.; Rakowski-DuBois, M. ; Elliott, C. M. J. Electrochem. Soc., 1989, 136, 1040 .

7. (a) Casewit, C. J.; Haltiwanger, R. C. ; Noordik, J.; RakowskiDuBois, M. organomet, 1985, 4, 119. (b) Radowski-DuBois, M.; Haltiwanger, R. C.: Miller, D. J.; Glatzmaier, G. J.Am. Chem. Soc., $1979,101,5245$.

8. Elliott, C. M.; Baldy, C. J.; Nuwaysir, L.; Wilkins, C. L. Inorg. Chem., 1990, 29, 389.

9. Baldy, C. J.; Morrison, D. L.; Elliott, C. M. Langmuir, in press.

10. Stoessel, S. J.; Elliott, C. M.; Stille, J. K. Chem. of Materials, 1989, 1,259 .

11. Baldy, C. J.; Elliott, C. M.; Feldberg, S. W. J. of Electroanal. Chem., 1990, 283, 53.

12. Albery, W. J.; Bloor, D.; Chen, Z.; Elliott, C. M.; Horrocks, B. R.; Monkman, A. T.; Mount, A. R.; Wilson, P. J. J. Chem. Soc. Faraday Transactions, 1989, 88, 247.

13. Albery, W. J.; Elliott, C. M.; Mount, A. R. J. Electroanal. Chem., 1990, 288, 15. 
- 14. Elliott, C. M. : Kopelove, A. B.; Albery, W. J.: Chen, Z. J. Phys. Chem., 1991, 95, 1743. 

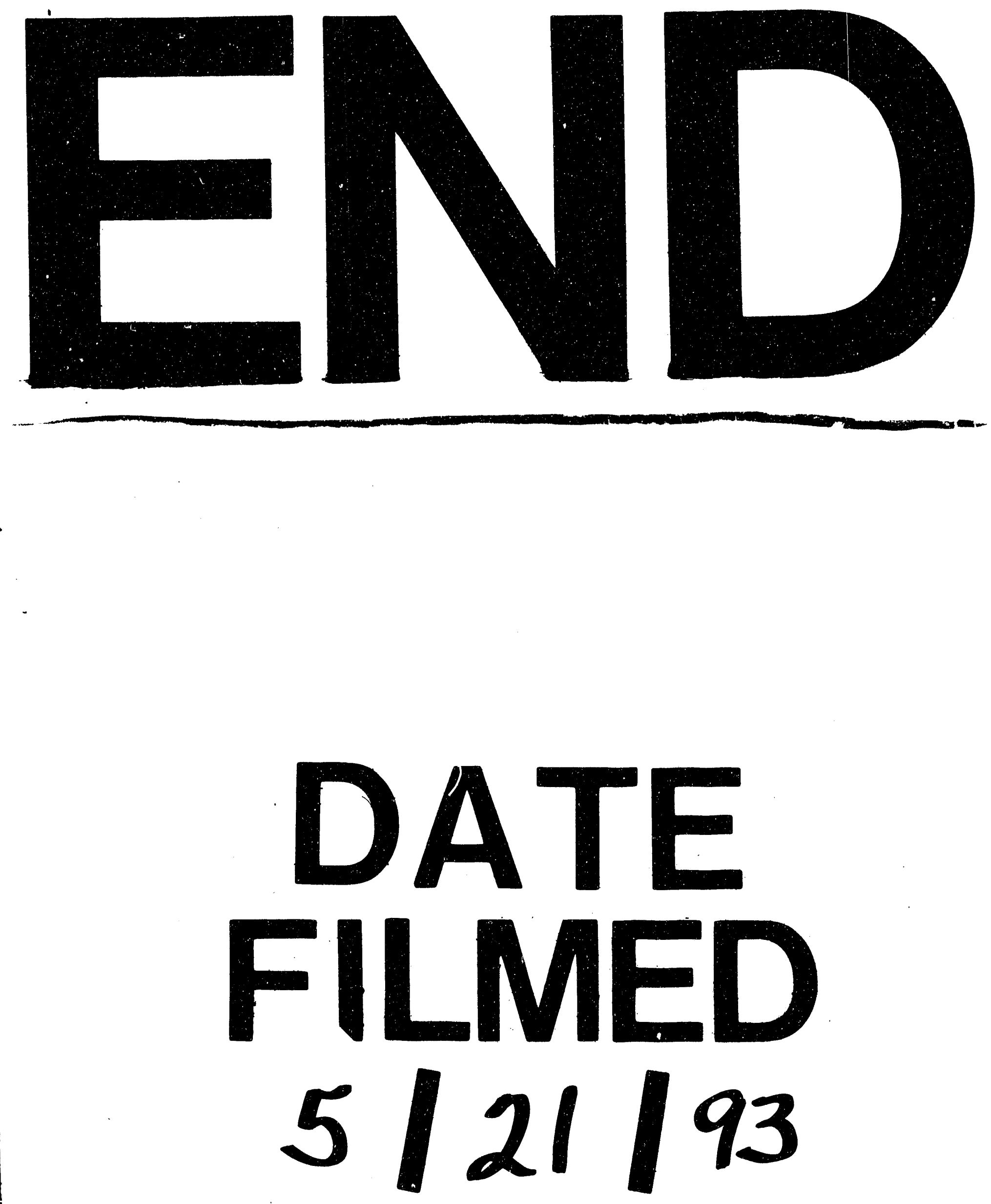
